Research Article

\title{
The Teaching Optimization Algorithm Mode of Integrating Mobile Cloud Teaching into Ideological and Political Courses under the Internet Thinking Mode
}

\author{
Yipei Jiao $\mathbb{( D}^{1}$ and Yu Liu $\mathbb{D}^{2}$ \\ ${ }^{1}$ Affiliated Hospital of North Sichuan Medical College, Nanchong 637000, Sichuan, China \\ ${ }^{2}$ School of Control Engineering, Chengdu University of Information Technology, Chengdu 610000, Sichuan, China \\ Correspondence should be addressed to Yu Liu; liuyu123@cuit.edu.cn
}

Received 21 August 2021; Accepted 3 November 2021; Published 10 December 2021

Academic Editor: Punit Gupta

Copyright (c) 2021 Yipei Jiao and Yu Liu. This is an open access article distributed under the Creative Commons Attribution License, which permits unrestricted use, distribution, and reproduction in any medium, provided the original work is properly cited.

\begin{abstract}
The purposes are to use the Internet technology to innovate the ideological and political (IAP) classroom teaching mode, take full advantage of the mobile platform under big data (BD), improve the effectiveness of IAP education, and deeply grasp the internal needs of students for the IAP classroom. First, the specific meaning and implementation process of mobile cloud teaching (MCT) under the Internet are deeply studied, as well as the connotation of the IAP course. Second, some suggestions are proposed. A theoretical analysis of the synergy between MCT and IAP classroom is conducted, and the teaching situation of cloud teaching classroom from the basic construction and operation mode of MCT platform is discussed. Finally, a case study on blue-ink cloud class is carried out. The results show that to realize the innovation of the IAP classroom teaching mode, it is considered that the IAP classroom has a strong dependence on the information. The MCT platform has wide access to information, which can well connect with the IAP classroom. The teaching methods of the cloud teaching platform tend to be diversified and interesting, and the overall teaching pattern is different from the traditional classroom teaching mode. The teaching effect is greatly improved based on the MCT platform. To achieve the synergy of the Internet and the MCT platform, the advantages of the cloud teaching platform should be expanded, the online communication between teachers and students should be strengthened, and the channels for information acquisition should be opened up. Blue-ink cloud class fully utilizes the advantages of the cloud teaching platform, which provides a great reference for IAP classroom teaching. Its flexible teaching method and intelligent management are helpful to the reform of IAP classroom teaching in the future.
\end{abstract}

\section{Introduction}

The world enters big data (BD), and Internet technology greatly affects people's learning, work, thinking mode, and so on. With the development of Internet technology, the teaching of teachers extends from classroom to network, from students to all who want to receive education, expanding the scope of work and the target being able to work according to their own interests and hobbies, free from time and place constraints, free from development space constraints. Through search engine technology, screening on the network of words, sounds, images: through hypertext, hyperlinks technology, and effective access to information and use. Self-centered information acquisition is more accurate and timely, which greatly improves learning and work efficiency. On the web, people can switch between tasks at any time, reading, writing, watching videos, and chatting and making friends at the same time. People can enter keywords and get all kinds of information through search engines; people are not only the receiver of information but also the sender and disseminator of information, which makes people become the media of information, and they are in the network of information without a center and edge. In the network age, people's thinking mode must also have the "nonlinear" characteristic of hypertextualization. Meantime, a series of 
reforms are carried out in various fields, such as artificial intelligence, smart city, cloud computing, and cloud teaching [1]. "Cloud teaching" with its rich educational resources, convenient use, diversified information content, and unique and fashionable education methods wins the favor of the vast majority of students [2], which also apparently impacts the thinking mode of contemporary students [3]. The rapid development of Internet technology around the world has changed the way of thinking again, and people have put forward the concept of "network thinking." As the latest form of the modern mode of thinking, the network thinking mode has the above "openness," "diversity" and "creativity." At the same time, it has made new breakthroughs in the horizontal, vertical and spatial structure, with an unprecedented "divergence." With the gradual growth of the students, the traditional teaching mode is unable to attract the students who live in the diversified information environment: (1) the teachercentered school education will ignore the existence of students as learning subjects; (2) school education focuses on books, and teachers will only faithfully implement textbooks, which will become an obstacle to students' creation and innovation; (3) the teaching method of schools is monotonous, and teachers only treat students as containers to receive knowledge; and (4) in the learning process, students have problems such as single method, single goal, single problem, single evaluation, single process, and so on. Building a multidimensional learning environment with pictures and texts through the "cloud teaching" mode will be welcomed by more students [4]. Ideological and political (IAP) education is correlated with the future of the motherland and social development, and it is a compulsory course for every student in all growth stages. Therefore, how to carry out IAP education is a very important issue for schools [5]. Especially during the two sessions in 2019, national leaders make important instructions on school IAP theory, that is, the tradition of IAP work advantages and information technology are highly integrated to enhance the sense of the times and attractiveness. This fully reflects that the Party attaches the importance to IAP education, points out the direction for the reform of IAP curriculum, and provides an action guide for the construction of information classroom [6]. The combination of IAP education and Internet technology adapts to the development trend of the times, uses the thinking mode of the Internet to deepen the effectiveness of IAP education, strengthen educational achievements, and improves the overall level of IAP education [7]. In the "Internet" era, the acquisition of knowledge is no longer limited to the classroom as it used to be. Diversified information channels make it easier for knowledge to be learned. However, the focus of IAP education is not on knowledge, but on the cultivation of students' psychological quality [8]. Search, recommendation, and advertising are the three most important ways to obtain information in the Internet age. Search, recommendation, and advertising are essentially solving the problem of information overload. The means and goals are different, and they are born in different stages of the product life cycle so that the system realization is different. The issues are that the academic circle concerns are how to guide students to study actively through the Internet-based MCT and help them establish a correct outlook on life, values, honor and disgrace [9], becoming worthwhile members of the society while realizing their values.

To realize the substantial innovation of the IAP classroom teaching mode in the Internet era, the cloud teaching platform is analyzed and discussed by searching for the literature, combination of practice and theory, and case analysis, especially the analysis of the teaching advantages and development potential of the blue-ink cloud class, which has great significance to the current IAP education in schools.

\section{Cloud Teaching and IAP Course}

2.1. Overview of MCT. In a broad sense, MCT is a kind of behavior of learning activities anytime and anywhere through mobile electronic devices [10]. The emergence of cloud teaching brings interest to learning, enriches the channels to acquire knowledge, liberates students from the boring classroom, makes up for the shortcomings of offline learning, and improves the efficiency of learning. In recent years, with the large-scale popularization of smartphones, MCT gradually develops and matures. It optimizes the course content and opens up practical functions, like online question answering and real-time interaction. With diversified tutoring materials such as short videos, audios, graphics, and PPT, students' interest in learning is greatly aroused [11]. In addition, there are abundant course resources, all stored in the cloud for the different needs of students. Moreover, they can directly connect with teachers. Open topics can also be discussed in groups. This learning mode stimulates the enthusiasm of students, promotes the interaction between teachers and students, and greatly improves the teaching quality [12]. Its speed is fast and clear, to avoid a large number of teachers not only save a lot of classroom teaching time, increase the amount of classroom information, and the teaching content is lively and lively, improve the efficiency of classroom teaching efficiency. It not only enriches the teaching content but also broadens the knowledge scope of the students.

MCT is a modern education method based on Internet technology and mobile devices for network information teaching. It skillfully combines mobile devices with $\mathrm{BD}$, and establishes a cloud teaching platform with cloud storage, cloud computing, cloud data and cloud website. Through the visual teaching mode, the mobile cloud constructs a platform to transform students' thinking mode and guide the students to learn autonomously $[13,14]$. The basic structure of cloud teaching is shown in Figure 1:

The MCT platform based on Internet BD promotes the reform of the teaching mode. Besides, in the process of establishing the platform, the platform aims to facilitate students to quickly grasp the operation methods of the platform and master various functions. Hence, it starts from students and centers on serving students to meet students' need and enhance the ability and the effectiveness of cloud teaching. 


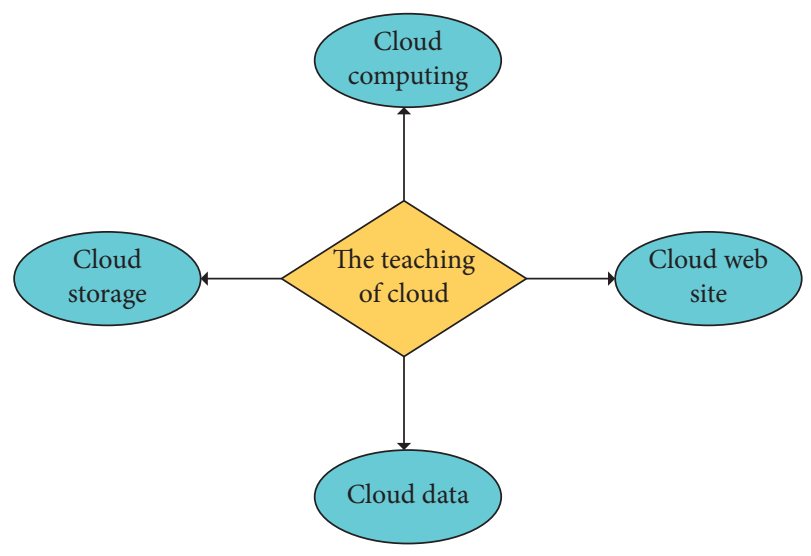

FIGURE 1: The basic structure of the cloud teaching.

2.2. Overview of the IAP Course. The content of the IAP course mainly includes the introduction to the basic principles of Marxism, the outline of modern Chinese history, the Mao Zedong Thought, and the theoretical system of socialism with Chinese characteristics, ideological and moral cultivation and legal basis, and formal policies [15]. It is the embodiment of the national core values, and a vital part of the national ideological and spiritual civilization construction. Every student needs to understand the theoretical system of socialism with Chinese characteristics and establish correct core values [16]. The IAP course has a lofty mission that other courses do not have to cultivate students' patriotic feelings, be loyal to the party and the country's beliefs, be good at using a dialectical perspective to look at problems, be good at observing the essence of things through phenomena, do well in grasping the main contradictions of things, always care about national affairs, devote themselves, repay the society, and grasp the direction of life in the tide of the times to realize the value of life. Because the IAP courses is extraordinary important, it is not easy to do a good job in IAP education. Although for many years, the party and the state emphasizes the construction of IAP education, often organize educators to carry out seminars on IAP education, and give targeted guidance [17]. However, as the science and technology and economy develop fast, the traditional IAP classroom is gradually unable to meet the needs of contemporary students. A new teaching mode should be established to optimize IAP class and improve students' interest in learning. In March 2019, national leaders hold a forum for teachers of IAP theory course in Beijing, which points out the need to "innovate classroom teaching" and realize "all staff, whole process and all-round" education.

\subsection{Innovation of the Teaching Mode of the IAP Course under} the Internet. The IAP course helps students understand themselves, society, and the world and establish a healthy and positive attitude toward life. The IAP course is a compulsory course for every student. Under $\mathrm{BD}$, the diversity and explosive information resources of the Internet promotes the innovation and development of IAP education. As for how to realize the perfect combination of the Internet and the IAP classroom, the problems to be considered are as follows: first, the IAP classroom is highly dependent on information and needs information with high authenticity and timeliness as the basic content; second, the essential characteristic of the Internet is the fast speed of information dissemination, and it has a more intuitive and broad vision to excavate information. The Internet utilizes media to represent social problems and ideology, which is the most advanced function currently, and needs to establish a good connection with IAP education; second, the Internet combined with mobile devices can achieve learning activities anytime and anywhere. Compared with traditional classroom learning, the cloud teaching mode has several prominent characteristics: (1) the teaching methods tend to be diversified and interesting; the teaching pattern is completely different from the traditional classroom teaching; and it includes language form, the content, learning media [18]. The effect of IAP education is improved based on Internet technology. The key concepts and the overall pattern of cloud teaching are shown in Figure 2:

(2) The Internet technology deepens the communication between teachers and students, and their relationship is closer. Online answering and discussion make the learning effect significantly improved, achieve the objectives of strengthening IAP education, and fully show the Internet's connectivity function. (3) Through the mobile platform, students can fully express their ideas and opinions, and teachers can be informed of the specific learning situation of students and teach them in accordance with their aptitude. (4) Internet technology contributes to the centralized management of students, which is a very convenient management method for schools, teachers and students. In general, Internet technology provides a new teaching mode for IAP education and is vital in improving the effectiveness of IAP education [19].

2.4. Synergy of MCT and the IAP Classroom. The Internetbased cloud teaching system and the IAP teaching system need to cooperate with each other to produce synergy. Only in this way can the advantages of cloud teaching give a full play and optimize the IAP classroom greatly.

2.4.1. Magnifying the Advantages of MCT. Education is a process of value embodiment and the value output of educators to learners. The traditional teaching mode only focuses on the output form of educators and neglects the acceptance of knowledge by learners. The establishment of the mobile platform and the use of Internet technology can analyze BD and make the IAP educators fully understand students' dynamics, interests, problems, and opinions on the course. Thus, they can have a deep understanding of students' learning needs and guide students to form a rightthinking mode and correct their learning methods.

2.4.2. Increasing Online Communication between Teachers and Students. The inheritance of knowledge is a process of mutual recognition, and the MCT platform strengthens the interaction between teachers and students through the real- 


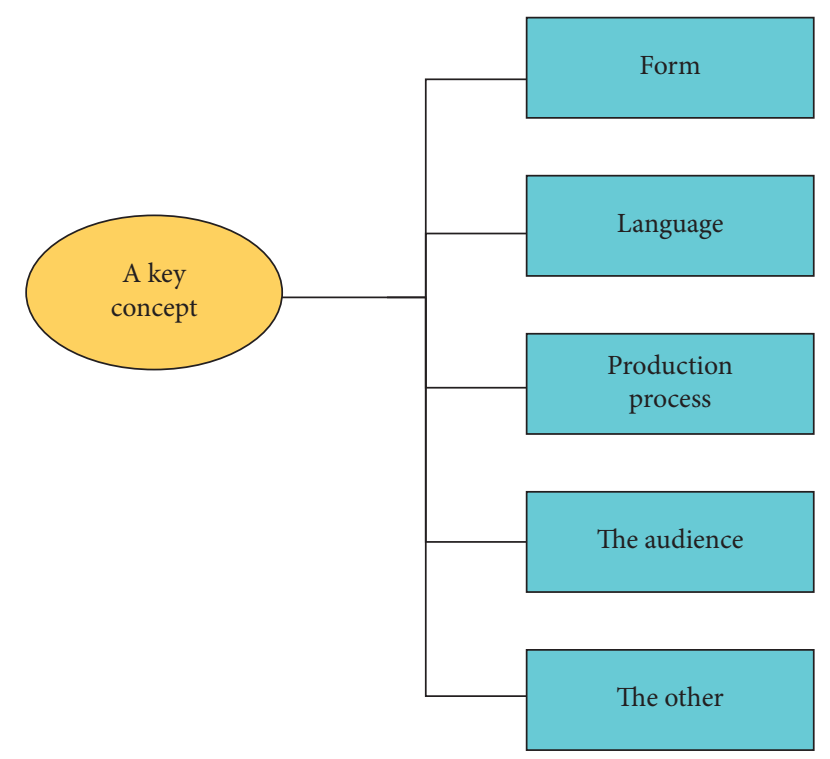

FIgURE 2: Key concepts and the overall pattern of the cloud teaching.

time teaching mode and one-to-one online answering. It takes individual students as the center; promotes the contact between teachers and students, teachers and parents, between students, and between teachers; and helps establish a comprehensive teaching system on a quid pro quo basis. The system can make teachers get feedback on students' learning status at the first time, and help them select the teaching content and make a teaching plan for the next period, improving the teaching quality.

2.4.3. Opening Up Information Access Channels. The biggest advantage of the MCT platform is its wide range of information sources. However, this information is highly fragmented and inconsistent, which posts an obstacle for students to collect more professional information.

2.4.4. Strengthening the Integration of Cloud Teaching and the IAP Education Classroom. The teaching mode is in line with the development of the times, which is a new experience for both students and teachers. The content of the classroom teaching becomes rich and interesting because of the diversity of media. The most important difference between the mobile platform and the traditional teaching method is that each student is the main body of the classroom, and students can seize the initiative of the classroom by sending barrage, comments, and praise. In addition, the interaction between teachers and students is conducive to grasping the rhythm of the classroom for teachers because teachers can appropriately add the beginning and ending, which makes the teaching process more complete [20].

2.4.5. Grasping the Core Idea and Making the Collaborative Progress. In the new era, with the development of the country and society, the demand for talents is increasing. While imparting knowledge, educators also need to pay special attention to students' IAP education. Schools and teachers must cultivate students' socialist core values and patriotism and guide students to have the right self-understanding, realize their values and have a lifelong goal. This requires that the MCT classroom must maintain a serious and lively style and does not put the cart before the horse while adding interesting elements to the learning process. The original intention of intelligent teaching is to educate students to have a correct worldview, values, and philosophy.

\subsection{Significant Advantages of MCT}

2.5.1. Diversified Teaching Methods. The MCT platform based on the Internet has the potential to improve the teaching mode of IAP courses because it has unique and wide dissemination of information, rich information access channels, and interactive platform. It conforms to the divergent and open characteristics of the IAP classroom. With the universality of mobile intelligent devices in society, more and more colleges and universities utilize its advantages of fast-speed and wide-coverage to strengthen their IAP teaching. The MCT enriches the traditional teaching modes, and students can get the latest information anytime and anywhere and learn knowledge from practice instead of learning from books alone, making them profoundly understand the knowledge. The knowledge acquisition channels of cloud teaching are major social platforms, such as MicroBlog and WeChat, official websites, various professional knowledge forums, academic papers, and journals database. Furthermore, some of these resources are interactive and still some can be shared with each other, which meet the demand for more information resources and extend the in-class knowledge to the practice, greatly improving the learning efficiency, imperceptibly guiding students to form a right-thinking mode [21].

2.5.2. Digitalization of the Teaching Process. The advantage of the MCT platform lies in the application of data cloud disk. On the one hand, it is reflected in the acquisition and update of teaching resources. The powerful functions of BD and cloud disk enable the platform to obtain massive resources anytime and anywhere, truly realize mobile teaching, and break the limitations of traditional classroom and knowledge database. Especially for the IAP classroom, the acquisition of real-time resources can cultivate students' habit and ability to pay attention to national affairs, strengthen students' ability to analyze and capture hot issues, guide students to treat things objectively, calmly and correctly in real life, and change their thinking mode imperceptibly. Besides, through the storage function of cloud disk, the course can be broadcasted or replayed, and they can review the key points and difficult knowledge repeatedly, which greatly improves the efficiency of the classroom and solves the problem of students' uneven ability level, so that every student can get a full education. On the other hand, online learning belongs to face-to-face teaching. Students and teachers can interact in real-time, which is convenient 
for teachers to know students' learning situations, and is conducive to creating a lively classroom atmosphere. More importantly, based on the digital teaching and management mode, students' learning situations can be intelligently evaluated and tested, and the targeted training and intelligent management can greatly help improving the effectiveness of classroom teaching. Specifically, students' classroom performance can form historical data to upload to the cloud, and the cloud system can make timely feedback, aided by strong support BD analysis and Internet intelligent computing technology. Each student's learning ability is intelligently graded. This reduces the burden on teachers, and the results are accurate and effective. The MCT platform collects and analyzes the collected student data, continuously optimizes and upgrades the curriculum, brings more perfect curriculum and teaching experience for teachers and students, promotes the organic unity of teaching and learning, and improves the teaching quality in the process of continuous integration of cloud teaching and IAP classroom [22].

2.6. Case Analysis. Currently, there are MCT platforms with similar functions in the market, and their operation modes are almost the same, but they have their advantages in teaching mode and operation management mode. The blueink cloud class is selected because it has research value. It is a MCT platform developed by the Beijing Blue-Ink Big Data Technology Research Institute, and its core competitiveness lies in the teachers' groups-building and students' participation in the class. Students can watch the content released by the teacher in each group for the preview before the class. Since the launch of the blue-ink cloud class, its powerful mobile teaching function wins the unanimous praise of teachers and students and is widely recognized by many scholars. Nearly 10 million teachers and students benefit from the blue-ink cloud class. To further investigate the real use of blue-ink cloud class, a satisfaction questionnaire is designed and 500 copies are randomly distributed to primary and secondary school students in a city. The results of the questionnaire are shown in Tables 1 and 2.

\section{Analysis of the Teaching Mode of the Blue-Ink Cloud Class}

3.1. Analysis of the Results of the Survey on Satisfaction of the Blue Ink Cloud Class. The results of the questionnaire are shown in Figure 3:

According to the results of the questionnaire, $72 \%$ of the students are very satisfied with the use of blue-ink cloud class, $14 \%$ of the students are basically satisfied, and also $14 \%$ of the students are not satisfied. Therefore, the satisfaction of the blue-ink cloud class is high, but it still needs continuous improvement. In terms of the operation mode of the blueink cloud class, $57 \%$ of the students think that the classroom teaching mode is the most attractive, and $22 \%$ of the students hold the idea that its after-class management is advanced, and its online clock out and comprehensive evaluation functions can improve the management efficiency; finally,
$68 \%$ of the students argue that they will introduce the use of the blue-ink cloud class APP to their friends, which shows the APP has strong attraction and user stickiness, and the classroom effectiveness is guaranteed as well.

3.2. The Realization of the Teaching Mode. The classroom teaching mode of the blue-ink cloud class is very innovative. It is mainly divided into three parts: before-class, in-class, and after-class. The learning modes of different parts are shown in Figure 4:

3.2.1. Autonomous Learning before Class. Teachers assign preview tasks and send them to the cloud system of blue-ink cloud class in the form of computer files, and students download and complete the tasks on their mobile devices to understand the core content of the course in advance.

3.2.2. Teacher-Student Interaction in Class. The teacher divides the difficult points according to the content of the course. For the more important knowledge points, the multifunctional equipment can be used for teaching. Besides, the teacher can solve the problems with the students through questions, tests and other interactive links, grasp the rhythm of the classroom, reassign study enthusiasm, and ensure that the students actively participate in the classroom. The specific implementation of the interaction with students in class is shown in Figure 5.

Generally, interactive teaching can be divided into three modules:

The first is the "questioning." Teachers set questions based on the course content to guide students to think and answer, using the "Questionnaire" function of the blue-ink cloud class.

The second is "communication." The teacher inspires the students around the difficulties and key points of the course, divides the students into groups and discusses them separately. Through the "Question answering and discussion" function of the blue-ink cloud, the discussion results of each group are summarized and analyzed to understand the students' thoughts, which then guide and correct them pertinently.

The third is "evaluation." Before class, the teacher registers the students' attendance through the "blue-ink assistant." In class, the teacher checks the students' understanding and memory of knowledge through the classroom test provided by the cloud class. Finally, the results of the group discussion are added and summarized for comprehensive evaluation. In addition, other functions, like questionnaire surveys and extracurricular videos, can be used to get grade the growth value and acquire the attributions.

3.2.3. Sharing after Class. The function of "brainstorming" is set up after the end of the course in the blue-ink cloud class. The purpose is to guide students to actively discuss the problems that students encounter in the learning process and suggestions about the course and extend them to 
TABLE 1: Basic information of samples.

\begin{tabular}{lccc}
\hline Grades & Primary school & Junior middle school & Senior high school \\
\hline Distributed number of the questionnaire & 200 & 200 & 100 \\
\hline
\end{tabular}

TABLE 2: Questions on the questionnaire.

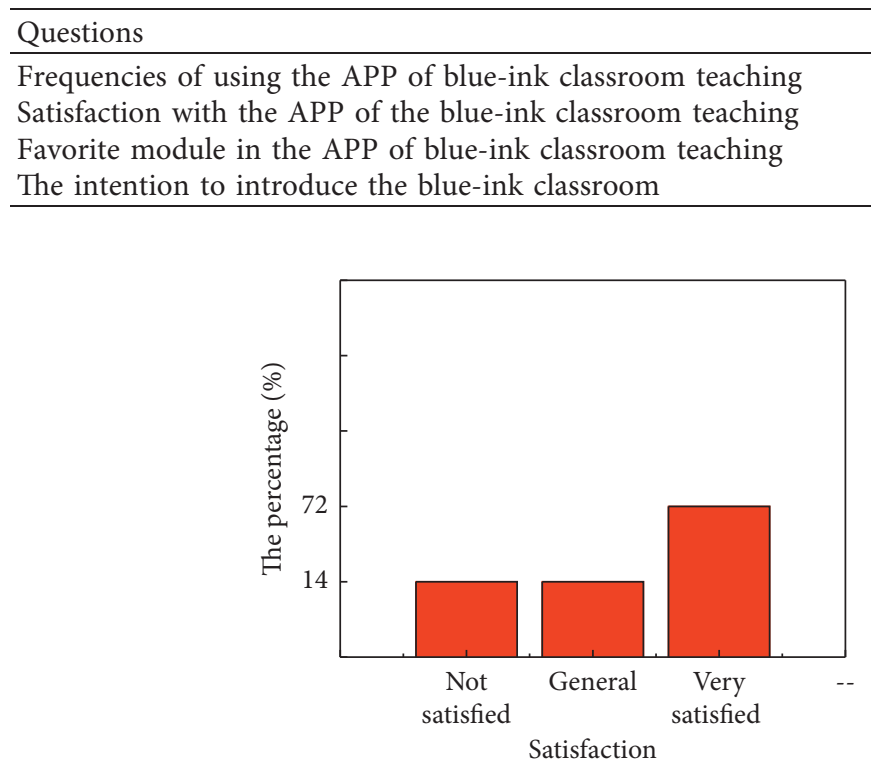

(a)

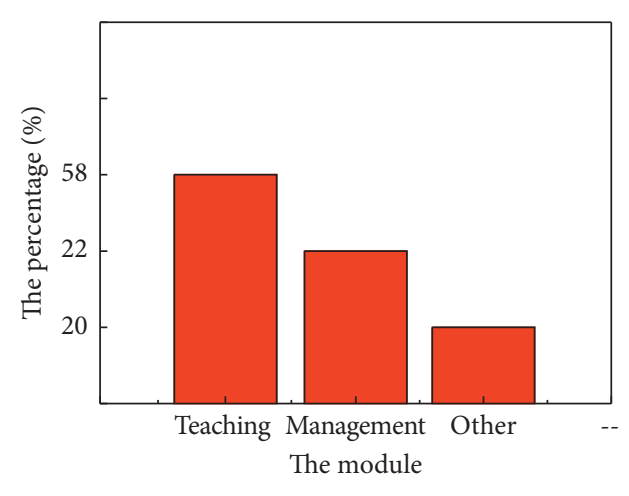

(b)

Figure 3: Results of the questionnaire of the blue-ink cloud class: (a) user satisfaction (b) the attraction of different modules to users.

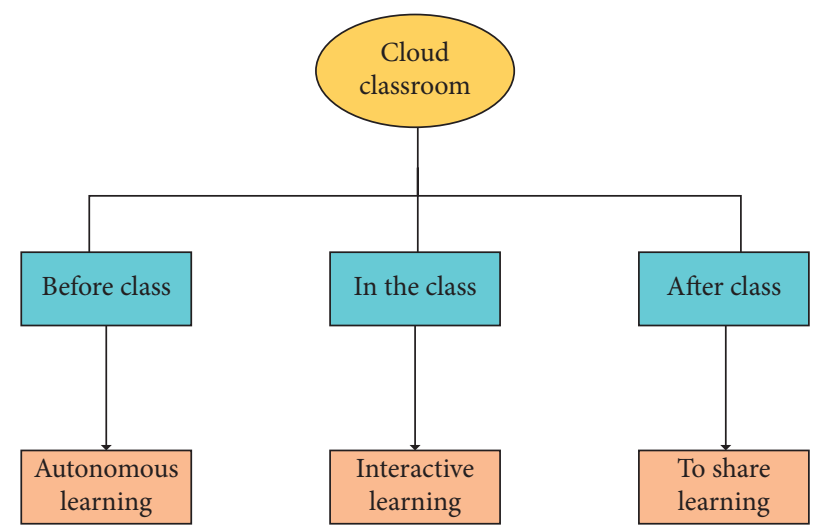

Figure 4: The teaching mode of the blue-ink cloud class.

extracurricular knowledge application to realize the collision of thinking sparks, improve students' independent thinking ability and finally, share the completion of the course to the social platform to gain learning experiences.

3.3. Advantages and Potentials. The advantages of the blueink cloud class teaching mode over the traditional teaching mode in the teaching practice are shown in Table 3:

The first is the acquisition of rich learning resources: with the help of blue-ink cloud mobile database, it can provide rich and diverse massive materials for classroom teaching; the second is the optimization of teaching methods: blue-ink cloud class adheres to the actual needs of teachers and students, strives to create a lively and relaxed classroom atmosphere, sets up a scientific and reasonable multifunctional classroom management mode, and realizes the transformation of the teaching mode from the traditional "a teacher to the whole classroom" to "face-to-face," which promotes the interaction between teachers and students; third, it is close to life, convenient and fast: it breaks the traditional way of learning in schools, realizes the learning anytime and anywhere, helps students break through the restrictions, and enhances students' sense of achievement and acquisition. 


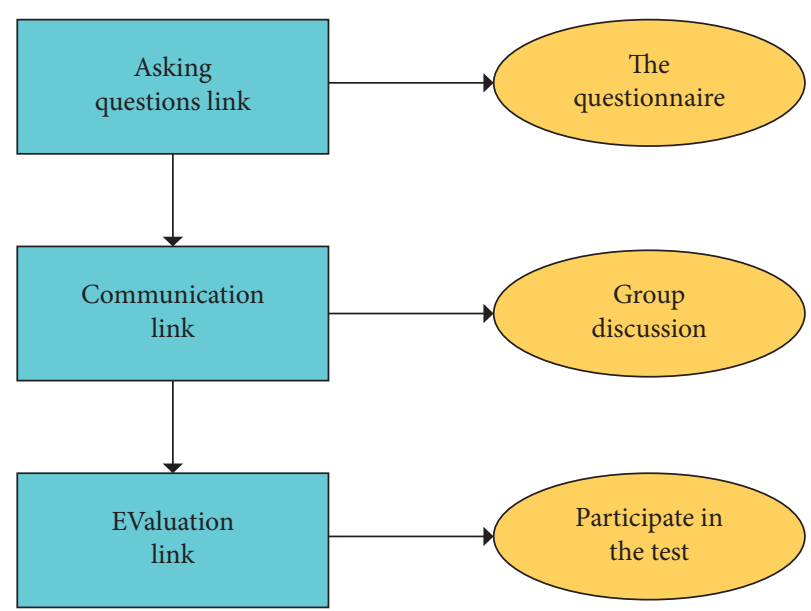

Figure 5: The specific implementation of cloud class teaching.

TABLE 3: Comparison between the blue-ink cloud class and traditional teaching mode.

\begin{tabular}{lcc}
\hline Teaching mode & Traditional & Blue-ink cloud class \\
\hline Learning content & Textbooks only & A number of learning materials and extracurricular resources \\
Teaching methods & Teachers' explanation & Face-to-face interactions between teachers and students \\
Learning places & In schools & Anytime and anywhere \\
\hline
\end{tabular}

\section{Conclusion}

The rise of MCT platforms based on the Internet is the need of the development of the times, and it also meets the needs of students and teachers. With the popularity of electronic devices, mobile teaching is gradually becoming one of the main teaching methods. Especially in the classroom of IAP education, real-time data updates and cloud data resources storage make IAP education no longer as dull as before. In addition, the synergy of MCT and the IAP classroom arouses students learning enthusiasm, reduces their addiction to mobile phones and also changes students' thinking and learning methods, promoting the integration of IAP courses and cloud teaching.

The shortcomings are as follows: the MCT platforms have their advantages and disadvantages, and only the blue-ink cloud class platform is selected, neglecting other MCT platforms. The advantages and potentials of cloud teaching still need further research. The Internet-based MCT platform possesses the capacity for development. The problems need to be further studied: how to correctly guide students to transform from "passive learning" to "active learning"; how to transform teaching structure from "teacher-centered" to "teacher-student centered"; how to make full use of the diverse teaching functions to achieve effective collaboration with modern teaching technology and IAP classroom; and how to improve the teaching effect with new teaching methods, which has great significance for reforming the teaching methods of IAP education.

\section{Data Availability}

No data were used to support this study.

\section{Conflicts of Interest}

The authors declare that there are no conflicts of interest.

\section{Acknowledgments}

This study was supported by the General Project of Open Problems of Si Chuan Network Culture Research Center in 2017 (WLWH17-11).

\section{References}

[1] L. Wang, "Research on the teaching mode of Internet + mobile cloud class," Contemporary Education Practice and Teaching Research, vol. 5, no. 656, pp. 15-16, 2017.

[2] Y. Yao, "Application of mixed teaching model based on mobile cloud platform in ideological and political theory course in higher vocational colleges," Youth, no. 22, pp. 221-224, 2019.

[3] Y. Liu, "Empirical research on learning situation data analysis based on mobile cloud teaching platform-taking dynamic website design course of independent college as an example," Computer Engineering and Science, vol. 41, no. 1, pp. 119-123, 2019.

[4] J. Zhou, "On blended teaching model of college English reading course based on blue-ink cloud class," Literature Review, no. 16, pp. 132-133, 2017.

[5] T. Tang, "Teaching reform of higher vocational professional courses in the "Internet + " era-taking E-commerce as an example," Electronic Commerce, vol. 3, no. 3, p. 79, 2017.

[6] Y. Wang and Y. Wang, "Transformation of teaching mode supported by intelligent education service," Chinese Journal of Medical Education Technology, vol. 33, no. 6, pp. 37-41, 2019.

[7] X. Liu and Y. Zhao, "Research on the effective English teaching model and strategy of blue-ink cloud class based on 
mobile cloud teaching," Think Tank Times, vol. 168, no. 52, pp. 151-159, 2018.

[8] Y. Demchenko, A. Belloum, W. Los, T. Wiktorski, and S. Brewer, "EDISON data science framework: a foundation for building data science profession for research and industry," in Proceedings of the IEEE International Conference on Cloud Computing Technology and Science, vol. 40, no. 34, pp. 160162, Luxembourg, Luxembourg, December 2017.

[9] T. E. Smith, P. S. Rama, and J. R. Helms, "Teaching critical thinking in a ge class: a flipped model," Thinking Skills and Creativity, vol. 28, no. 7, p. 17, 2018.

[10] A. R. Rao and R. Dave, "Developing hands-on laboratory exercises for teaching STEM students the internet-of-things, cloud computing and blockchain applications," in Proceedings of the 2019 IEEE Integrated STEM Education Conference (ISEC), vol. 20, no. 2, pp. 37-34, Princeton, NJ, USA, March 2019.

[11] J. Amantha, V. Kumar, M. A. Sanmugam, and S. Osman, "Mobile applications for learning: exploring information technology undergraduates' preference in Malaysia," Journal of Computational and Theoretical Nanoscience, vol. 17, pp. 1113-1116, 2020.

[12] K. F. Mwakisole, M. M. Kissaka, and J. S. Mtebe, "Feasibility of cloud computing implementation for eLearning in secondary schools in Tanzania," International Journal of Education and Development Using Information and Communication Technology, vol. 6, no. 14, pp. 23-33, 2018.

[13] L. I. Jie and S. O. Business, "Research on cloud classroom teaching practice of insurance practice based on mobile terminal," Journal of Zhejiang Fashion Institute of Technology, vol. 39, no. 10, p. 223, 2018.

[14] T. Germain-Williams, "Teaching children to love problem solving (a reference from birth through adulthood)," Developing Toddler Thinking, vol. 10, no. 104, p. 15, 2017.

[15] X. U. Ding-Hua, Z. B. Luo, X. U. Xiao-Hong et al., "Research on internet plus medical image teaching model based on the online interactive cloud teaching platform," Medical Education Research and Practice, vol. 33, no. 2, p. 17, 2019.

[16] J. V. Biljon and V. Ronell, "Trends, drivers and barriers influencing Cloud Computing Services for mobile interactions in teaching and learning//Conference on," Information Communications Technology \& Society, vol. 24, no. 1, p. 7, 2018.

[17] X. Huiying and M. Qiang, "College English cross-cultural teaching based on cloud computing MOOC platform and artificial intelligence," Journal of Intelligent and Fuzzy Systems, vol. 23, no. 14, pp. 1-11, 2020.

[18] J. A. Kumar, S. Rajamanickam, and S. Osman, "Exploring the use of mobile apps for learning: a case study on final year engineering undergraduates in Malaysia," ASM Science Journal, no. 3, pp. 63-67, 2020.

[19] P. Janardhana, K. Reddy, and G. Singaravelu, "Augmented reality (AR): the new trend in transforming teaching and learning in education," International Journal of Analytical and Experimental Modal Analysis, vol. 12, no. 4, pp. 620-626, 2020.

[20] O. Debauche, M. Sad, and S. A. Mahmoudi, "Internet of things: learning and practices. Application to smart city," in Proceedings of the IEEE International Conference on Cloud Computing Technologies and Applications, vol. 10, no. 33, p. 17, Brussels, Belgium, November 2019.

[21] B. N. Anderson, "When learning sinks in: using the incubation model of teaching to guide students through the creative thinking process," The Gifted Child Today, vol. 42, no. 13 , p. 6, 2019.

[22] H. Rezk, A. E. Amin, and D. Maha, "E-management educational system based on mobile cloud computing," International Journal of Computer Applications, vol. 181, no. 50, pp. 15-20, 2019. 